are clearly a people of wonderful courage and energy ; they are constructive; they are willing to be governed and have a government; the whole nation is at work. The downfall of Germany is due to the destruction of its government: only the appearance of a Bismarck can save it. We may well take warn- ing. We seem to show no constructive power; the politicians are at fault, without imagination, without outlook; our moral attitude towards work, in all classes, is unsound. Unless our science can be made effective we shall soon be nowhere.

Henry E. Armstrong.

\title{
The Present Position of the Ergot Problem.
}

\begin{abstract}
$A$ MONG well-known drugs, ergot has always occupied a peculiar position. A parasitic fungus, which after many disastrous epidemics was recognised as a scourge, ultimately became the chief medicament of the obstetrician. The numerous attempts of the nineteenth century to isolate its active constituents now appear of little value, but the fundamental discovery by Tanret in 1875 of the crystalline alkaloid ergotinine, $\mathrm{C}_{35} \mathrm{H}_{39} \mathrm{O}_{5} \mathrm{~N}_{5}$, still stands out. Unfortunately this substance does not produce the characteristic effects of ergot to any considerable extent; much later a second alkaloid, ergotoxine, $\mathrm{C}_{35} \mathrm{H}_{41} \mathrm{O}_{6} \mathrm{~N}_{5}$, discovered simultaneously by Barger and Carr in Great Britain, and by Kraft in Switzerland, was, however, found by Dale to have a powerful physiological action, and to produce, for example, the characteristic gangrene. The subsequent discovery, by Barger and Dale, of small amounts of powerfully active, nonspecific amines in ergot extracts led some clinicians, particularly in Germany, to substitute these amines for ergot, and to neglect the specific alkaloids.

Attention has been recently again focussed on the latter by A. Stoll, of Basle, who gives in Die Naturwissenschaften for August 17 and 24 a résumé of earlier researches and of his own work. In certain varieties of ergot Stoll has discovered two new crystalline alkaloids of the formula $\mathrm{C}_{33} \mathrm{H}_{35} \mathrm{O}_{5} \mathrm{~N}_{5}$. One of these, ergotamine, was found by Spiro to resemble ergotoxine in action, and more recently Dale and Spiro, in a joint paper, declared ergotamine and ergotoxine to be pharmacologically identical. There are therefore no complications on the biological side. Ergotamine can be converted into a less soluble and less potent isomer ergotaminine, which in some respects is analogous to Tanret's ergotinine. Stoll has thus
\end{abstract}

discovered a new pair of alkaloids, showing great similarity to the older pair. The physiologically potent member of each pair has the same action, a finding which, according to Stoll, also results from unpublished experiments of Rothlin. Chemically the new pair are also closely related to the old, by colour reactions, decomposition products, optical rotation, etc. Ergotamine and ergotaminine both differ from ergotinine by $\mathrm{C}_{2} \mathrm{H}_{4}$, and from ergotoxine by $\mathrm{C}_{2} \mathrm{H}_{6} \mathrm{O}$, the elements of a molecule of ethyl alcohol.

Yet all attempts to convert one pair of alkaloids into the other pair have failed, and for the present they may be regarded as homologues. From some specimens of ergot Stoll obtained only ergotamine, from others only ergotoxine; sometimes both alkaloids were isolated. Yet the identity of the action of these two alkaloids is remarkable, and without parallel among homologues. Are they perhaps both formed from a common precursor by the different methods of extraction employed? Are they perhaps converted into the same active substance in the body? Their puzzling relationship certainly deserves further investigation, which is, however, rendered difficult by the scarcity of suitable material, greatly accentuated by the War.

This seems to be the present position of the ergot question. The résumé under review deals in a useful manner with the older work, and shows how during the last two decades our knowledge of the active principles of ergot has been placed on a solid foundation, largely through English and Swiss work. Most of the investigations of the last century the writer dismisses as valueless. His own important contributions are of the kind we might expect from one who was associated with Willstätter in the study of chlorophyll.

\section{Clothes Moths and their Control. ${ }^{1}$}

AONG entomologists there are well known to be A two very common moths the larvæ of which are destructive to fabrics; namely, the case-making clothes moth (Tinea pellionella L.) and the webbing clothes moth (Tineola biselliela Hum.); the tapestry moth (Trichophaga tapetzella L.) is much less frequent but is occasionally destructive. In the case-making clothes moth, the larva makes a portable habitation out of its silk, together with fragments of the material upon which it feeds. It withdraws completely into the case when resting, but when feeding or moving it protrudes its head and foremost body-segments. Pupation also takes place within the case, which is sealed up and anchored to the fabric or other object. The webbing clothes moth is the most abundant species of the three; its larva does not construct a portable case, but spins silken tunnels wherever it crawls over the material which it is consuming. When fully fed it constructs a silken cocoon intermixed with particles of fabric and excrement; this pupal shelter, therefore, is quite different from that of the species previously mentioned. In the rarer tapestry moth the larva constructs silk-lined burrows through the substance of the material which it infests.

I 1 Clothes Moths and their Control, by ₹. A. Back. U.S. Dept. of Agric. Farmer's Bull. 1353, July 1923. 28 pp. with 2 I figs.
In general, the larvæ of clothes moths feed upon wool, fur, feathers, hair, and all fabrics manufactured from them. It will therefore be realised that they may be found attacking not only clothing but also carpets, rugs, furs, upholsteries, stuffed animals, brushes, felts in pianos, and the like. The moths are relatively short-lived; they take no nourishment and are in themselves harmless. Their eggs are laid upon or between folds of fabrics or within the meshes of the latter. They are readily crushed by brushing, etc., and are very fragile. Under average indoor conditions they hatch in about a week, this period being subject to lengthening or shortening according to temperature. The larvæ are relatively long-lived and require from about fifteen weeks to two years to complete their development. Much depends upon the nature of the material upon which they are feeding and the temperature conditions under which they exist. The pupal, or resting, period varies from about eight days in warm summer weather to a month or more in winter. In the British Isles the moths are commonest between June and October, and their larvæ are feeding the great part of the remainder of the annual cycle.

Methods of dealing with these pests are numerous. Fabrics that are well brushed or beaten every two weeks are seldom seriously affected: exposure to

NO. 2824 , VOL. I I 2 ] 
direct sunlight is also a valuable measure. Articles of clothing that require to be stored are immune from attack if sealed down in paper bags, or very securely wrapped in several layers of quite unbroken newspaper. Naphthalene, in the form of flakes or balls, should be placed among the clothing thus fastened up. It also acts as a deterrent when placed in drawers or cupboards, but is not entirely effective under such conditions. Paradichlorobenzene appears to be as valuable as naphthalene, but camphor is decidedly less effective.

On a large scale, the cold storage of furs, carpets, and furniture is the most certain of all preventives, and this method is coming more and more into use. Extensive infection of carpets, upholsteries, etc. in large houses, hotels, etc. may need fumigation in order to eradicate clothes moths completely. An effective remedy, which is also non-injurious to furniture, fabrics, plate, or other household goods, is the application of hydrocyanic acid gas. Its manipulation requires the services of an intelligent person who understands the dangers of its use and knows how to administer it. Carbon tetrachloride is also effective, and has the advantage over hydrocyanic acid gas in being neither explosive nor inflammable. Fumigation with sulphur is a well-known remedy, but there is some danger from fire in its application, while it has a bleaching effect on many delicate fabrics, wallpaper, etc., besides tarnishing metals. Carbon disulphide is also recommended, but its vapour is inflammable. Dry heat is now recognised as an effective agent in killing insects. All fabrics will be freed from pests in a very short time if exposed to a temperature of $130^{\circ} \mathrm{F}$. Lower temperatures have been found effective against clothes moth larvæ; the latter when exposed in an incubator at $128^{\circ}, 120^{\circ}$, and $110^{\circ} \mathrm{F}$. died in 6 , II, and $3 I$ minutes respectively. Fabrics dipped in water heated to $140^{\circ} \mathrm{F}$. will be found to contain no living eggs or larvæ of clothes moths.

It may also be mentioned that there are a number of worthless remedies against these insects, including powdered sulphur, hellebore, and borax; also lavender flowers, cayenne pepper, reasonable strengths of tobacco powder, and other substances are of no value in keeping away these insects. A. D. Imms.

\section{Science in Agriculture.}

THE somewhat belated appearance of the annual report of the Rothamsted Experimental Station for the year $192 \mathrm{I}-22$ does not deprive it of the perennial interest which must always attach to the doings of this institution. For historically, Rothamsted can claim to be almost the earliest example of the benefits that result from the application of science to industry. From the economic point of view, the discoveries of Lawes and Gilbert take a very high rank in the history of scientific achievement. The most remarkable feature of the early work of Rothamsted was the success with which field and laboratory work were combined. With the ever-growing complexity of all regions of knowledge, it has become increasingly difficult to maintain this tradition. The refinements (the application of statistical methods may be instanced) which modern field research demands, and the revolution in many of the fundamental conceptions of science, are two factors. On the applied side, another obstacle is the smaller apparent margin for improvement in the practice of modern husbandry. Whereas the discoveries of the early workers were productive of changes in farm practice of the order, in terms of economic results, of Ioo per cent., in these days, improvements are only possible to the extent, as it were, of ro per cent.

A recognition of this fact is implied in the statement contained in the report that "the most important development of recent years has been the reorganisation of the work of the Station so as to bring it into touch with modern conditions of agriculture on one side and of science on the other: it is hoped to reorganise in the near future the farm and field work and to improve the field technique." It unquestionably adds to the difficulties of this reorganisation that it should coincide with a period when the whole economic basis of arable farming is so precarious as it is to-day. It is being openly said that arable farming, and particularly the growing of cereals, cannot be made to pay in present circumstances.

In dealing with the finance of the farm attached to the Station, the report states that "from I920 onwards, the financial results are deplorable, and they show clearly why many of the arable farmers to-day are in their present position." The report does not specifically indicate the most promising line of investigation calculated to remedy this disastrous state of affairs, but there can be little doubt that the Department of Soil Physics, of which the assistant director, Dr. B. A. Keen, is the head, and to which precedence is given in the report, should be so regarded. Under the heading, "The Cultivation of the Soil," some account is given of investigations which promise to yield results which may indicate to the farmer methods by which the cost of cultivation can be reduced, and "costs of cultivation. dominate the future of arable farming." In this connexion it may be significant that the American farmer apparently has been able to grow wheat at a profit with a yield of 16 bushels to the acre, whereas the British farmer with a return of 32 bushels is losing money. It is a reasonable deduction that it pays better to reduce the costs of cultivation than to aim at maximum production. In other words, the British farmer may still be paying. court to methods the chief recommendation of which is their superior artistry.

In the section headed "The Feeding of the Plant," it is interesting to learn that "broad beans die prematurely unless they receive a homeopathic dose of boric acid in addition to the so-called "complete" plant food." It is remarkable that a discovery parallel to that of the rôle of accessory food factors in animal nutrition should have been made in relation to plants.

The volume of purely scientific work done at Rothamsted would appear to be considerably greater than that carried on in relation to so-called applied science. As many as fifty-two scientific papers were published during the year by members of the staff. Of these, two were of Royal Society rank, namely:"The Mathematical Foundations of Theoretical Statistics" (R. A. Fisher), and "A Quantitative Investigation of the Bacterial and Protozoal Population of the Soil " (D. W. Cutler, L. M. Crump, and H. Sandon).

The financial support which the Station now receives from the State is considerable. For the year under notice grants from the Development Fund totalling $22,030 l$. wrere received. In I9I 2 the total was approximately $3000 l$. It must be a source of gratification to the director, Sir John Russell, that so great an expansion should have taken place during his term of office.

NO. 2824 , vOL. I I 2$]$ 